\title{
Efficacy of Tamsulosin in the Medical Management of Juxtavesical Ureteral Stones: A Randomized Control Trial
}

\author{
Mustafa ASMF ${ }^{1}$, Islam MS ${ }^{2}$, Mamun $\mathrm{AA}^{3}$, Khalid MS ${ }^{1}$ \\ ${ }^{1}$ Department of Surgery, Narayanganj General Hospital, Narayanganj, Bangladesh \\ ${ }^{2}$ Department of Urology, Bangabandhu Sheikh Mujib Medical University, \\ Dhaka, Bangladesh \\ ${ }^{3}$ Department of Surgery, Shaheed Suhrawardy Medical College, Dhaka, Bangladesh \\ e-mail: syeefkhalid007@gmail.com
}

\begin{abstract}
Urolithiasis is the third most common disease of the urinary tract. Among all urinary tract stones, majorities are ureteral stones located in the distal part of the ureters. At present, multimodalities of treatment are available to the urologists. The purpose of the present study was to observe the efficacy of Tamsulosin in conventional treatment of juxtavesical ureteric stone having size up to $8 \mathrm{~mm}$. This was a single centered, parallel randomized control trial carried out in the outpatient department of Urology, Bangabandhu Sheikh Mujib Medical University (BSMMU), Dhaka from July 2007 to June 2008. The patients with unilateral, juxtavesical ureteral stone with normal functioning kidney and absence of clinical and laboratory signs of urinary tract infection and stone size up to $8 \mathrm{~mm}$ were included in the study. Patients were divided into two groups according to the computer generated simple random sampling. Patients of Group-A were given conventional hydrotherapy treatment and patients of GroupB were given Tamsulosin $0.4 \mathrm{mg} /$ day along with the conventional hydrotherapy. Each patient was followed-up weekly until stone expulsion for 4 weeks. In Group-A and Group-B, the mean age with SD was $38.55 \pm 10.05$ and $37.7 \pm 9.33$ years. Expulsion occurred in $32(53.33 \%)$ of 60 patients in Group-A and $51(85 \%)$ of 60 patients in Group-B $(p<0.05)$. The number of pain episodes in this study was statistically significantly lower in Group-B patients compared to Group-A $(p<0.05)$. Urinary tract infection was encountered in $12(20 \%)$ patients of Group-A and $2(3.33 \%)$ patients of Group-B $(p<0.05)$ during four weeks therapy which was treated by appropriate antibiotics. No side effects of Tamsulosin were encountered in any patients of Group-B which could require the cessation of the medication or might need for dose titration. Findings of the study revealed that the Tamsulosin supplemented conventional therapy is more effective than conventional hydrotherapy alone in management of juxtavesical ureteral stones.
\end{abstract}

Keywords: Juxtavesical ureteral stones; Tamsulosin; Medical management; Randomized control trial

\section{Introduction}

Stone disease is one of the most common afflictions of modern society. ${ }^{1}$ Urolithiasis affects $4-15 \%$ of world population and the incidence of this disease is increasing day by day. ${ }^{2}$ Of all the urinary tract stones, $20 \%$ are ureteral stones, and $70 \%$ of these ureteral stones are found in the distal part of the ureters. ${ }^{3}$ The goal of treatment of patients suffering from ureteral calculi is to achieve complete stone clearance with minimal morbidity. At present, multimodalities of treatment are available to the urologists like expectant treatment, noninvasive procedure like extracorporeal shockwave lithotripsy, minimal invasive procedures like ureteroscopy or laparoscopy and open surgical intervention. ${ }^{4}$
Ureteral calculi of any size may be associated with renal obstruction and care must be taken to prevent irreversible damage to kidney, whether patient selects expectant or active treatment. ${ }^{4}$ An expectant treatment or watchful waiting approach may be expected to produce spontaneous stone expulsion up to $50 \%$ of cases but some complications such as urinary infection, hydronephrosis, and repetitive colicky pain may occur. ${ }^{5,6}$ Noninvasive treatment with extracorporeal shockwave lithotripsy and minimal invasive approach with ureteroscopy allow ureterolithiasis to resolve in almost all cases but these procedures are not risk free and they require some experience and not cost effective., 5 On the contrary, the role of medical expulsive therapy in the treatment of this pathological condition is 
still unclear. ${ }^{8}$ In particular, the most effective treatment regimen for spontaneous stone expulsion and control of painful symptoms have not been yet determined despite the widespread need in clinical practice. Although each alternative has some advantages and disadvantages, none guarantees a stone-free state, which depends on many factors. ${ }^{9}$ Although stone size and location are the main factors affecting stone clearance, the internal anatomic structure of the ureter and stone composition also seem to be unmodifiable factors. In the distal ureter, seventy one to ninety eight percent of stones of $<5 \mathrm{~mm}$ and $25-53 \%$ stones with a diameter of $5-10 \mathrm{~mm}$ are reported to pass spontaneously with watchful waiting approach. ${ }^{5}$

Tamsulosin, an alpha $1^{-}$adrenergic antagonist usually used in symptomatic case of BPH owing to its inhibitory effect on alpha ${ }_{1 \mathrm{~A}}$ receptors in relaxing prostatic and bladder neck smooth muscles. ${ }^{10}$ It has also effect on alpha $1 \mathrm{D}$ adrenoceptors of ureteric smooth muscles in facilitating expulsion of stone from its juxtavesical part. $^{11}$ Few studies in different countries have been performed to evaluate the role of Tamsulosin in facilitating expulsion of juxtavesical ureteral stones. But so far no such study has been undertaken in this country. For this reason, this prospective study was performed to assess the role of alphatadrenoceptos antagonist Tamsulosin in facilitating the spontaneous expulsion of juxtavesical ureteral stones.

\section{Materials and Methods}

Study design and Population: This was a single centred, parallel, double blind randomized control trial. This study was carried out in the Outpatient Department of Urology, BSMMU, Dhaka from July 2007 to June 2008. The patients with both sexes above 18 years of age with unilateral, juxtavesical ureteral stone with normal functioning kidney and absence of clinical and laboratory signs of urinary tract infection and stone size up to $8 \mathrm{~mm}$ were included in this study. Before recruitment, for baseline data, each patient was evaluated by history, physical examination and investigations like urine routine and microscopic examination, culture and sensitivity test, serum creatinine measurement, intravenous urography, ultrasonography of KUB and prostate and other biochemical and haematological tests. A data sheet was used to record the information.
Patients with multiple stones, severe hydronephrosis with a history of spontaneous stone expulsion, distal ureteral surgery, diabetes mellitus, peptic ulcer disease, hypotension, patients getting calcium antagonists, stone size more than $8 \mathrm{~mm}$, and anatomical deformity at vesicoureteric junction, single kidney and bladder outflow obstruction were excluded from this study.

Randomization: All the patients fulfilling the inclusion and exclusion criteria were recruited. After duly taking written informed consent patients were divided into two groups which were generated randomly by software and were named as Group-A and Group-B.

Intervention: Patients of Group A were given conventional treatment consisted of hydration with minimum two liter water intake daily, physical exertion and analgesics if required (50mg diclofenac sodium suppository with $\mathrm{H}_{2}$ blocker). On the other hand, patients of Group-B were given Tamsulosin $0.4 \mathrm{mg} /$ day along with the conventional treatment. Each of the patients continued the therapy.

Follow up and outcome measures: Each patient was followed-up weekly until stone expulsion for four weeks. All patients of both groups were asked during weekly follow-up about stone expulsion time, episodes of colic, analgesic use and side effects of drug. Follow up cases were seen in urology outpatient department. In each of the follow-up study history, clinical examination, urine routine microscopic examination, plain $\mathrm{X}$ ray of KUB region and ultrasonography of KUB region were done and data on stone expulsion were recorded in data sheet. The criteria for treatment discontinuation as well as the need of hospitalization and/or endoscopic treatments were pain uncontrolled by analgesic therapy, fever, progressive hydronephrosis, increased creatinine level, unsuccessful expulsion after four weeks and patient desired to remove the stone before day 28 .

Ethical consideration: Prior to the commencement of the study, the research protocol was approved by the Ethical Committee of BSMMU

Statistical Analysis: Collected data were edited by meticulous checking and rechecking. Statistical Package for Social Science (SPSS), a statistical analysis package program version-17 was used. 
Measures of dispersion (mean, standard deviation) and the tests of significance (paired $t$ test, student's unpaired $t$ test, $\mathrm{Z}$ test and Chisquare test) were employed to examine the statistical significance of the study. A $p$ value $<0.05$ was taken as minimum level of significance.

\section{Results}

A total of 246 patients were assessed for eligibility of which 135 patients were selected as study population. Among them 7 patients were withdrawn before randomization due to noncooperation. The remaining 128 patients were randomly allocated into Group A consisted of 64 patient and Group B of 64 patients. During the study period 4 patients from Group-A and 4 patients from Group-B discontinued the intervention. Hence, they were dropped out and finally results of 60 cases from each group were compared. The mean age $( \pm \mathrm{SD})$ for group A was 38.5 ( $\mathrm{SD} \pm 10.05$ ) years (age range $18-60$ years) and for Group B was 37.7 (SD \pm 9.33 ) years (age range 18-59 years). Age of the patients of each group were compared and found no significant difference (table I).

Table I: Mean Age of the patients in study groups

\begin{tabular}{lcc}
\hline Group & Mean \pm SD & $p$ value* \\
Group A & $38.5 \pm 10.05$ & $>0.05$ \\
Group B & $37.7 \pm 9.33$ & \\
\hline
\end{tabular}

In Group-A, 19 (31.7\%) patients were in stone size between 3 to $5 \mathrm{~mm}$ and $41(68.3 \%)$ patients were in stone size between 6 to $8 \mathrm{~mm}$. In Group-B, $18(30 \%)$ patients were in stone size between 3 to $5 \mathrm{~mm}$ and $42(70 \%)$ patients were in stone size between 6 to $8 \mathrm{~mm}$. In both groups, the distribution of stone size showed no statistical significance (table II).

Table II: Distribution of mean stone size among the study population

\begin{tabular}{lccc}
\hline Group & $\begin{array}{c}\text { Stone size } \\
\text { Mean } \pm \mathbf{S D}(\mathbf{m m})\end{array}$ & $\begin{array}{c}\text { Calculated } \\
\mathbf{Z} \text { value }\end{array}$ & $p$ value \\
Group A & $5.88 \pm 1.23$ & $0.304^{\mathrm{ns}}$ & $>0.05$ \\
Group B & $5.94 \pm 0.92$ & & \\
\hline
\end{tabular}

In group A and B rate of stone expulsion from the ureter were $53.3 \%$ cases and $85.0 \%$ cases respectively. There was significant difference in clearance of stone between the groups (table III), but the rate of Expulsion varies according to size shown in figure 1 and figure 2.

Table III: Rate of Stone expulsion in study groups.

\begin{tabular}{lccccc}
\hline Group & $\begin{array}{c}\text { Stone } \\
\text { expulsion }\end{array}$ & $\begin{array}{c}\text { Failure of } \\
\text { expulsion }\end{array}$ & Total & $\begin{array}{c}\text { Calculated } \\
\chi^{2} \text { value }\end{array}$ & p value \\
\hline Group A & 32 & 28 & 60 & & \\
& $(53.33 \%)$ & $(46.67 \%)$ & $(100.0)$ & & \\
Group B & $51(85 \%)$ & $9(15 \%)$ & 60 & $12.658^{*}$ & $<0.05$ \\
& & & $(100.0)$ & & \\
Total & $83(70.8 \%)$ & $37(39.2 \%)$ & 120 & & \\
& & & $(100.0)$ & & \\
\hline
\end{tabular}

Figure 1: Rate of expulsion in smaller stone (3-5 mm)

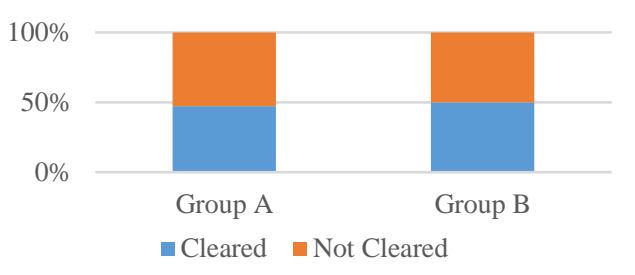

Figure 2: Rate of expulsion in larger stones (6-8 mm)

Fig. II:Rate of expulsion in larger stones (6-8 mm)

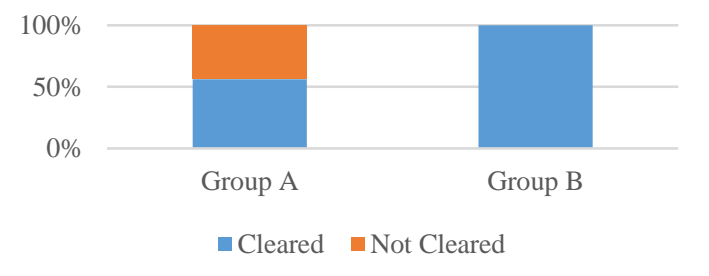

The mean episodes of pain in patients of Group A and Group B were respectively $4.13 \pm 1.704$ and $2.58 \pm 1.519$ respectively, shown in table IV;

Table IV: Pain episodes in two study groups.

\begin{tabular}{clccl}
\hline $\begin{array}{l}\text { Group } \\
\text { No of } \\
\text { Patients) }\end{array}$ & $\begin{array}{l}\text { No of } \\
\text { Sufferer } \\
(\%)\end{array}$ & Mean \pm SD & $\begin{array}{l}\text { Calculated } \\
\text { Z value }\end{array}$ & $\begin{array}{l}p \\
\text { value }\end{array}$ \\
\hline $\begin{array}{c}\text { A } \\
(60)\end{array}$ & $48(80 \%)$ & $4.13 \pm 1.704$ & & \\
B & $36(60 \%)$ & $2.58 \pm 1.519$ & $5.11^{\mathrm{s}}$ & $<0.05$ \\
$(60)$ & & & & \\
\hline
\end{tabular}

Difference was statistically significant $(p<0.05)$ In group $\mathrm{A}$ and $\mathrm{B}$ urinary tract infection was detected in $20 \%$ and $3.33 \%$ patients respectively and the difference was statistically significant $(p<0.05)$ significant. 


\section{Discussion}

Though there is no exact data about the prevalence of ureterolithiasis in Bangladesh but the problem is quite common. Multimodalities of treatment are available to the urologists. Minimal invasive therapies such as extracorporeal shockwave lithotripsy and ureteroscopy have been widely introduced for treatment of ureteric stones during last two decades. ${ }^{12}$ The efficacy of these treatments has been proved by several studies. ${ }^{13}$ However, although such procedures are rather effective, thy are not free of risk or inconveniences and are quite expensive. ${ }^{5}$ On the other hand, conventional treatment like simple watchful waiting approach with two litters of daily water intake can result in complications such as urinary tract infection, repeated colicky pain or hydronephrosis and can affect renal function. ${ }^{12}$

However, this treatment may not always be sufficient, especially for stones located at the intramural ureter, where smooth muscle tonus is more evident. ${ }^{13}$ Studies have revaled that alpha ${ }^{-}$ adrenergic antagonists inhibit basal tone, peristaltic activity and ureteral contractions. ${ }^{8}$ Generally, the main obstacle to the transport of lower ureteral stones is the intramural detrusor tunnel $;^{7}$ thus blocking these receptors could affect stone passage. Tamsulosin is a competitivealhpa $1^{-}$ adrenergicantagonist having higher affinity for alpha $_{1 \mathrm{~A}}$ and alpha $\mathrm{iD}_{\mathrm{D}}$ adrenoceptors. These receptors are located in smooth muscle of prostate bladder neck, detrusor, vesicoureteric junction and ureter specially lower part. ${ }^{12}$ The blockade of alpha adrenergic receptor by a specific antagonist like Tamsulosin results in decreased ureteralperistaltic amplitude and frequency with a consequent loss of intraureteral pressure and thereby an increase in fluid transport ability. Thus the effect of Tamsulosin on the obstructed ureter is to induce an increase in the intramural pressure gradient around the stone as well as decreased peristalsis below the ureter and consequently a derease in intramural pressure below the stone in association with the decrease in basal and micturition pressure even at the bladder neck. All these mechanisms bolster the urge to expel the stone. ${ }^{10,16}$

The present study was designed to prove the efficacy of Tamsulosinin addition to conventional treatment for the management of juxtavesical ureteric stone having size up to $8 \mathrm{~mm}$. A total of 120 patients were grouped into two on alternate basis, 60 patients in group A treated with conventional therapy consists of hydration, physical exertion and analgesics. 60 patients of group B were given Tamsulosin $0.4 \mathrm{mg}$ daily along with the conventional treatment. Therapies in both groups continued for 4 weeks or until stone expulsion within 4 weeks. In complete obstruction, the signs of renal injury appear in three to four weeks. For this reason, the spontaneous passage of stones can be waited on for 4 weeks. ${ }^{3}$ The mean age with SD in Group-A and Group-B were $38.55 \pm 10.05$ and $37.7 \pm 9.33$ years. No significant difference was observed among the two groups in relation to age and sex. This creates an equal group, so that these didn't cause any effect to the outcomes.

In this study, mean stone size was $5.88 \pm 1.23 \mathrm{~mm}$ (range 3.8) for Group-A and $5.94 \pm 0.92 \mathrm{~mm}$ (range 3.5-8) for Group-B. There was no significant difference between two groups with respect to stone size. The above distribution correlates with the study done by Cervenakov et $\mathrm{al}^{14}$ having stone size between $3-10 \mathrm{~mm}$ in each group but does not correlate with the study conducted by Dellabella et al ${ }^{11}$ having stone size $4-11 \mathrm{~mm}$ and $3.8-13 \mathrm{~mm}$ in conventional and Tamsulosin group respectively.

Episodes of pain in this study was statistically significantly lower in Group-B patients compared to Group-A $(p<0.05)$. Mean episodes of pain in patients of Group-A was $4.13 \pm 1.704$ and that in Group-B was $2.58 \pm 1.519$. Patients in the study by Yilmaz $\mathrm{E}$ et $\mathrm{al}^{12}$ suffered from pain episodes of $2.42 \pm 1.39$ and $1.72 \pm 0.88$ without and with Tamsulosin respectively.

In the current study, stone expulsion occurred in 83(69.2\%) of 120 subjects enrolled. Expulsion occurred in $32(53.3 \%)$ of 60 patients in Group-A and $51(85.0 \%)$ of 60 patients in Group-B. Statistical analysis showed a significantly higher stone expulsion rate in Group-B compared with Group-A ( $p<0.05)$ which is more or less similar to the study conducted by Cervenakov et al ${ }^{14}$ where stone expulsion rate was $62.8 \%$ in standard treatment group and $80.4 \%$ in group where standard treatment was supplemented by Tamsulosin. Similarly, study conducted by Yilmaz $\mathrm{E}$ et $\mathrm{al}^{12}$ Tamsulosin group showed 
$79.31 \%$ stone expulsion in comparison to $53.57 \%$ stone expulsion in group without Tamsulosin. A meta-analysis done by Lu Zet $\mathrm{al}^{17}$ worked on twenty-nine trials with a total of 2,763 patients. The pooled analysis showed a19\% improvement in stone clearance with tamsulosin. But Dellabella $\mathrm{M}$ et $\mathrm{al}^{11}$ in a study showed stone expulsion rates were $100 \%$ and $70 \%$ in group treated with and without Tamsulosin respectively, These high rates of stone expulsion might be due to use of steroid (Deflazacort) in both groups.

In this study, effect of stone size on expulsion rate was observed. In smaller stones (3-5mm range), Group-A and Group-B included 19 and 18 patients respectively. Expulsion occurred in 9 $(47.36 \%)$ patients of Group-A and 9 (50\%) patients of Group-B; difference was not statistically significant $(p>0.05)$ but in relation to larger stones (6-8mm range), expulsion seen in 23 $(56.09 \%)$ patients of Group-A and $42(100 \%)$ patients of Group-B, difference was significant $(p$ $<0.05$ ). A systematic review by Somani BK et al ${ }^{15}$ claimed a result similar to our finding. But Dellabella $\mathrm{M}$ et $\mathrm{al}^{11}$ in their study did not find any correlation between stone size and expulsion rate of stone.

In this study, complications like urinary tract infection, repeated colicky pain were encountered during study period. Urinary tract infection was encountered in 12(20\%) patients of Group-A and $2(3.33 \%)$ patients of Group-B during four weeks therapy and was treated by appropriate antibiotics. Difference is statistically significant $(p<0.05)$. Above findings correlate with different studies conducted by Cervenakov et al, ${ }^{14}$ Dellabella et a ${ }^{11}$ and Yilmaz E et al. ${ }^{12}$ No serious side effects of Tamsulosin were encountered in any patients of either group, which could require the cessation of the medication or need for dose titration. Ten patients of Group-A and 8 patients of Group-B complained of mild headache and palpitation. In studies conducted by Dellabella et al and Porpiglia et al to enable spontaneous passage of distal ureteral stones, steroids have generally been included in medical treatment. However, in this study no steroid was used. The steroid sparing approach was another important feature of this study.

\section{Conclusion}

Tamsulosin has a potentially important role for conservative expulsive therapy of juxtavesical ureteral stones, broadening pharmacological indications rather than endoscopic treatments for the resolution of this disease. Considering the findings of the present study and the studies previously done by others, it may be concluded that Tamsulosin supplemented conventional therapy is more effective than conventional hydrotherapy alone in the management of juxtavesical ureteral stones. Further studies are recommended to validate the promising and statistically significant results of this study.

\section{References}

1. Margaret SP and Lotan Y. Urinary lithiasis: Etiology, Epidemiology and pathogenesis. In: Wein AJ, Kavoussi LR, Partin AW, Peters CA editors,: Campbell-Walsh Urology. $11^{\text {th }}$ ed. Philadelphia: Elsevier; 2016. p 1170-74.

2. Hesse A and Siener R. Current aspects of epidemiology and nutrition in urinary stone disease. World J Urol. 1997;15:165-71.

3. Leavitt DA, Rosette JJ, Hoenig DM. Strategies for Nonmedical Management of Upper Urinary Tract Calculi. In Wein AJ, Kavoussi LR, Partin AW, Peters CA, editors: Campbell-Walsh Urology. $11^{\text {th }} \mathrm{ed}$. Philadelphia: Elsevier; 2016. p1250-54.

4. Lingeman JE, Matlaga BR, Evan AP. Surgical management of upper urinary tract calculi. In. Kavoussi LR, Novick AC, Parton AW, Peters CA [editors]: Campbell-Walsh Urology. $\quad 9^{\text {th }} \mathrm{ed}$. Philadelphia: W.B. Saunders; 2007. p 1431-51

5. Segura JW, Preminger GM, Assimos DG et al. Ureteral stones: Clinical Guidelines Panel summary report on the management of ureteral calculi. J Urol. 1997; 158: 1915-21.

6. Miller OF, Kane CJ. Time to passage for observed ureteral calculi: A guide for patient education. J Urol. 1999; 162: 688-91.

7. Lotan Y, Gettman MT, Roehrborn CG, Caddeu JA and Pearle,MS. Management of ureteral calculi: a cost comparison and decision making analysis. J Urol. 2002; 1620: 21.

8. Dellabella M, Milanese G, Muzzonigro G. Randomized trial of the efficacy of Tamsulosin, Nifedipine and Phloroglucinol in medical expulsive therapy for distal ureteral stone. Journal of Urology. 2005; 174: 167-72. 
9. Whitfield HN. The management of ureteric stones. Part II: therapy. BJU International. 1999; 54(8): 91621

10. Yanardag H, Goktas S, Kibar Y Kilic S Erduran D. Intermittent Tamsulosin therapy in men with lower urinary tract symptoms. J Urol. 2005; 173: 155-58.

11. Dellabella M, Milanese G, Muzzonigro G. Efficacy of Tamsulosin in the medical management of juxtavesical ureteral stones. Journal of Urology. 2003; 170: 2202-05.

12. Yilmaz E, Batislam E, Basar MM, Tuglu D, Ferhat $\mathrm{M}$, Basar $\mathrm{H}$. The comparison and efficacy of 3 different $\alpha$ adrenergic blockers for distal ureteral stones. J Urol. 2005; 173: 2010-2012.

13. Kupeli B, Irkilatl L, Gurocak S, Tunc L, Kirac M, Karaoglan U et al. Does Tamsulosin enhance lower ureteral stone clearance with or without shockwave lithotripsy. Urology. 2004; 64: 1111-15.
14. Cervenakov I, Fillo J, Mardiak J et al. Speedy elimination of ureterolithiasis in lower part of ureters with the alpha1-blocker tamsulosin. Int Urol Nephrol. 2002; 34: 25-29.

15. Somani BK, Aboumarzouk O, Traxer $\mathrm{O}$ et al. Medical expulsive therapy for ureteral stones: where do we go from here? Nature Reviews Urology. 2016; 13:608-12.

16. Campschroer T, Zhu Y, Duijvesz D, Grobbee DE, Lock MTWT. Alpha-blockers as medical expulsive therapy for ureteral stones. Cochrane Database of Systematic Reviews 2014; 4:

17. Lu Z, Dong Z, Ding H, et al. Tamsulosin for Ureteral Stones: A Systematic Review and Meta-Analysis of a Randomized Controlled Trial. Urol Int. 2012; 89:107-15. 